\title{
EMPLOYING ORGANIC RANKINE CYCLE IN SMALL- SCALE APPLICATIONS FOR RECOVERING LOW TEMPERATURE HEAT: A REVIEW
}

\author{
Sakshi Mishra \\ Department of Mechanical Engineering \\ Acropolis Inst. of Tech. \& Research \\ Indore, M.P., India
}

\author{
Amit Kumar Kundu \\ Department of Mechanical Engineering \\ Acropolis Inst. of Tech. \& Research \\ Indore, M.P., India
}

\begin{abstract}
Organic Rankine cycle is a substitute method of producing energy from waste heat, fuel and gases at lowtemperature. Method (ORC) proved to be useful in decreasing environmental pollution as well as consumption of fuel. An organic Rankine cycle functions on the similar principle as a steam Rankine cycle, difference lying in lower operating temperature and pressure. These operational conditions are a result of replacing, working fluid in place of water into the closed loop system. This enables a lower grade heat to act as a fuel in ORCs. The organic Rankine cycle could be used in combination with a steam Rankine cycle to revoke waste heat and increase overall system efficiency. This paper will present a review analysis on the organic Rankine cycle (ORC), its Background, (ORC) configuration, its advantages and limitations, its small scale applications, choosing working fluids and trial study of expansion devices. Heat exchanger and expanders are regarded as economically costly parts in (ORC).
\end{abstract}

Keywords- ORC; Working Fluids; Small scale application; Waste heat recovery

\section{INTRODUCTION}

From last few decades, industrial and economic growth in many areas has necessitated tremendous increase in energy consumption through the escalation of the industrial sector and increase in domestic consumption. The increase in demand of energy has been met significantly by the substantial use of fossil fuels, leading to their depletion as well as atmospheric pollution.

These factors have stimulated the development of unconventional energy sources along with heat recovery technologies. Over the last decade, organic Rankine cycles (ORCs) have been studied extensively to harness low-grade heat sources that offer temperatures ranging from 80 to $400^{\circ} \mathrm{C}$. An ORC consist of the same components as a traditional Rankine cycle, a pump, an evaporator, a turbine (or expander) and a condenser. The major difference lies in the selection of working fluid: water is substituted by an organic component. [1]

Refrigerants having lower boiling temperatures than water such as pentane, butane, hexane and silicon oil, could be utilised as working fluids in organic Rankine cycles. Here, organic means compounds made up of carbon, hydrogen, and oxygen. Two foremost variations of ORC's $\mathrm{v} / \mathrm{s}$ steam cycles are the thermodynamic properties of the working fluid and the usually reduced dimensions of installations. Organic Rankine cycles have been studied both theoretically [2, 3] and experimentally [4] since the 1970s, and reveals efficiencies lesser than $10 \%$ for small-scale systems.

ORC efficiency increases at high pressure ratios. Expansion device is one of the major components of an ORC. Positive displacement machines are quite appropriate for these smallscale applications specifically scroll expanders' technology is used. [5]

Other vital factors should be well-thought-out when selecting expanders such as high isentropic efficiency, pressure ratio, power output, need for lubrication, intricacy, rotating speed, dynamic balance, consistency, price, working temperatures and pressures, leakage, noise and protection. [8] The first viable organic Rankine cycles using geothermal and solar heat sources were established between 1970 and 1980. Multiple organic Rankine cycles have been set up in some countries like USA, Canada, Italy and Germany, above that applications have also been stated in Finland, Belgium, Swaziland, Austria, Russia, Romania, India and Morocco. [1] Commercial usage of ORCs started in late 1970s and attention to this technology has grown considerably over the past decade.

Presently, we have more than 200 installed and operating ORC setups in the world producing installed power in excess of $1.5 \mathrm{GW}$. [6] Applications of ORCs consist of Biomass, Geothermal energy, Solar and Heat recovery. 


\section{ADVANTAGES OF ORC}

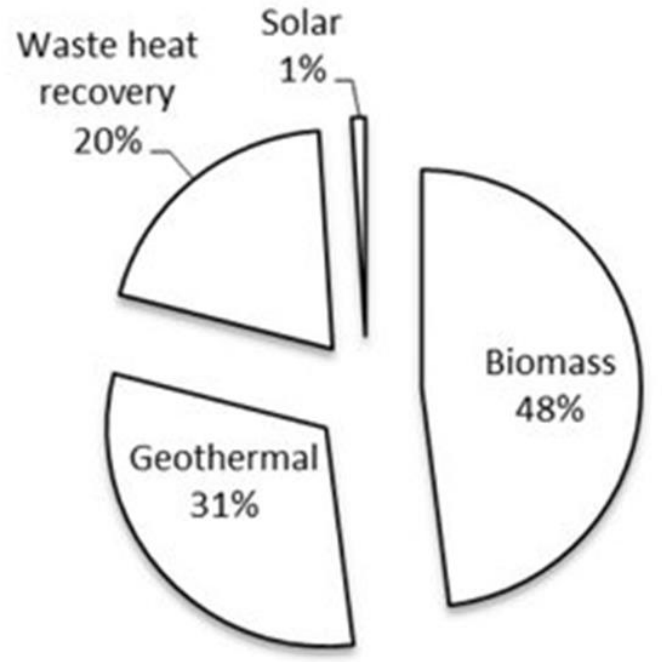

Fig 1: The ORC market for various sources of heat [9]

\section{ORC PROGRESSION}

1-2: Process comprises of pushing the working fluid from the condenser to the evaporator by increasing its pressure.

2-3: Evaporator has the purpose of increasing the temperature of working fluids by accumulating heat afore it passes to the expander.

3-4: The operating fluid increases its volume in expander with purpose to produce electric energy by conversion from mechanical energy.

4-1: Condensing the vapors of working fluid prior to repetition of cycle.

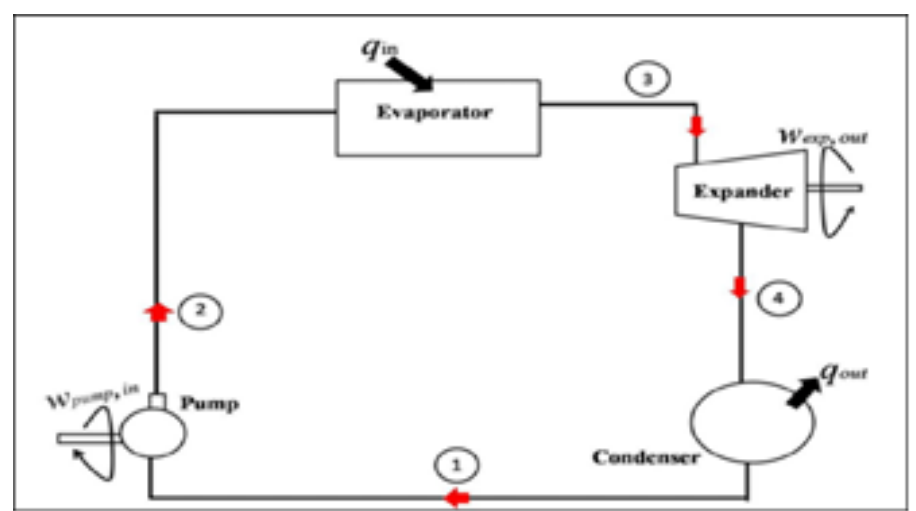

Fig 2: ORC Layout [11]
In addition to the ability to utilize ORC to recover waste heat normally unapproachable to conventional steam Rankine cycle, many more advantages are rendered by ORC:

-Lesser maintenance cost: Lower operating temperature and pressure in an ORC system with fewer components that are moving reduces the expenditure on maintenance to only a portion of analogous fossil-fuel generators.

-Minimal supervision required: The need for an operator to monitor ORC systems is disregarded because of lower operating pressure. Generally, the systems are automated and are remotely monitored control units.

-Improved equipment durability: A reduced amount of mechanical stresses are generated on the equipment since ORC systems functions at a lesser pressure and turbine speed. In addition, organic fluids are employed as an alternative of water thus moisture accountable for erosion of turbine blades during vapour expansion is eradicated.

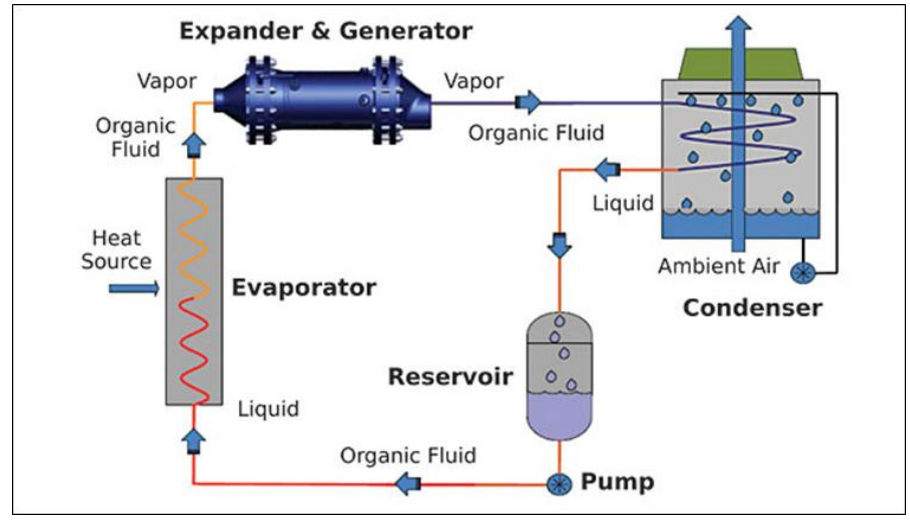

Fig 3: Process diagram for ORC presenting how organic fluids permits heat to be recovered from low temperature sources [10]

\section{HEAT RECOVERY USING ORC FROM SMALL SCALE APPLICATIONS:}

Lower temperature waste heat generally produced in small scale applications can be recovered capably by means of ORC technology, which implies that waste heat recovery applied to process applications that may not seem logical using other heat recovery technologies. First of all for any small scale application setup, various ways in which energy in the form of heat is wasted needs to be analyzed: 


\section{International Journal of Engineering Applied Sciences and Technology, 2020 \\ Vol. 5, Issue 1, ISSN No. 2455-2143, Pages 235-238 \\ Published Online May 2020 in IJEAST (http://www.ijeast.com)}

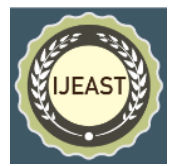

- Exhaust

- Flue gas

- Hot water/hot liquid

- Steam

- Radiation heat

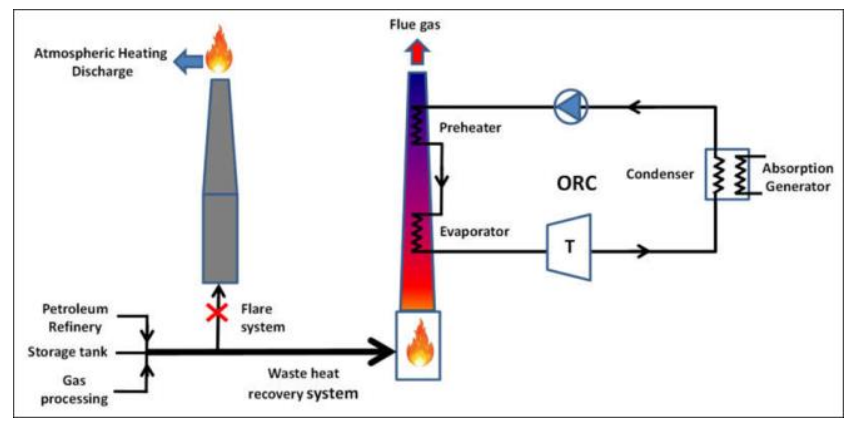

Fig 4: Example of application of ORC for waste heat recovery [12]

It could also be exhaust from a boiler, cooling water, or and radiant heat from hot equipment such as ovens, heaters, dryers, furnaces and burners etc. [10] Now the query is that what one should ruminate while picking an Organic Rankine Cycle. The answer to this probe is that by determining the source of heat. Usually either Steam or hot liquid are the most ideal choice of heat source for an ORC.

However the fact of distinction is that all the progressions cannot be applicants for waste heat recovery using an ORC. It's feasible to reclaim the heat from exhaust gases, nonetheless volumes and temperatures might be too little for providing monetary validation. In few scenarios for instance with radiation heat, the heat is nearly unmanageable to recuperate in monetary terms.

Additionally, it's also a task to supply flue gases that are uncontaminated and free of impurities like eroding gases as well as particulates. The addition of apparatus to resolve this concern augments the cost.

Overall, several considerations must be assessed before commencement of a waste heat recovery project.

-The volume flow rate of the exhaust gas.

-The thermal content/ temperature of the exhaust gas.

-The chemical conformation of the exhaust gas.
Aggregate obtainable thermal energy that could be recovered is decided by above aspects and is helpful for picking up optimal heat exchangers. After deciding on these factors, one should chose the vendor keeping all other factors in mind. The financial justification of the project with respect to expenditure incurred and energy recovered is prima fascia.

\section{CONCLUSION}

In expansion to the distinctive paybacks like savings of fuel as well as energy, it is vital to reflect on the immaterial benefits that incorporate those include increasing the energy efficiency at the same time reducing emissions and carbon footprint. To summarize, a noteworthy quantity of waste heat could be extracted by using ORC technology for uses in the process industry. The most suitable kind of ORC equipment is decided based on technical functionality, estimated capital savings and total cost of the project. The noticeable and insubstantial recompenses of an ORC program would help businesses cut expenses, mend their performance and stay ahead of the competition.

\section{REFERENCES}

[1] Georges E., Declaye S., Dumont O., Quoilin S., Lemort V., Design of a small-scale organic Rankine cycle engine used in a solar power plant, International Journal of LowCarbon Technologies, Volume 8, Issue suppl_1, July 2013, Pages i34-i41, https://doi.org/10.1093/ijlct/ctt030

[2] Probert, S.D.; Hussein, M.; O’Callaghan, P.W.; Bala, E. Design optimization of a solar-energy harnessing system for stimulating irrigation pump. Appl. Energy 1983, 15, 299-321.

[3] Monahan, J. Development of a 1-kW, Organic Rankine Cycle Power Plant for remote applications. In Proceedings of the Intersociety Energy Conversion Engineering Conference, New York, NY, USA, 12-17 September 1976.

[4] Badr, O.; O'Callaghan, P.W.; Probert, S.D. Rankine-cycle systems for harnessing power from low-grade energy sources. Appl. Energy 1990, 36, 263-292

[5] Lemort V, Quoilin S, Cuevas C, et al. Testing and modeling a scroll expander integrated into an Organic Rankine Cycle, Applied Thermal Engineering, 2009, vol. 29 (pg. 3094-102)

[6] Kamyar Darvish 1, Mehdi A. Ehyaei 2, *, Farideh Atabi 1 and Marc A. Rosen 3 Selection of Optimum Working Fluid for Organic Rankine Cycles by Exergy and ExergyEconomic Analyses Sustainability 2015, 7, 15362-15383; doi:10.3390/su71115362 sustainability ISSN 2071-1050 www.mdpi.com/journal/sustainability Published: 19 November 2015

[7] Peter Arvay, Michael R. Muller, Vishana Ramdeen,Economic Implementation of the Organic 
Rankine Cycle in Industry Rutgers University Glenn Cunningham, Tennessee Tech University @2011 ACEEE Summer Study on Energy Efficiency in Industry

[8] Al Jubori A.M., Al-Mousawi F.N., Rahbar K., Al-Dadah R., Mahmoud S.’Design and manufacturing a small-scale radial-inflow turbine for clean organic Rankine power system" Journal of Cleaner Production, Volume 257, 2020

[9] Osta Pereira, Sol-Carolina \& Mahkamov, Khamid \& Kenisarin, Murat \& Ismail, Mohammad \& Lynn, Kevin \& Halimic, Elvedin \& Mullen, David. (2019). Solar Salt Latent Heat Thermal Storage for a Small Solar Organic Rankine Cycle Plant. 10.1115/1.4044557]

[10] Maggie Yu ,Turning Process Waste Heat into Power Using Organic Rankine Cycle Technology, March 19, 2014,Access Energy https://www.processheating.com/articles/89973-turning-process-waste-heatinto-power-using-organic-rankine-cycle-technology

[11] Alhamadani, Ali \& Kareem, Aya. (2020). Review of Organic Rankine Cycle Used In Small- Scale Application. International Journal of Engineering Technologies and Management Research. $7 . \quad 52-63$. 10.29121/ijetmr.v7.i1.2020.496.

[12] Semmari, H.; Filali, A.; Aberkane, S.; Feidt, R.; Feidt, M. Flare Gas Waste Heat Recovery: Assessment of Organic Rankine Cycle for Electricity Production and Possible Coupling with Absorption Chiller. Energies 2020, 13, 2265. MDPI and ACS Style. 